\title{
IN VITRO EVALUATION OF MICRO-LEAKAGE OF A UNIVERSAL ADHESIVE USED WITH DIFFERENT ETCHING MODES IN COMPOMER RESTORATIONS
}

\author{
Betul Busra Ursavas', Tugba Bezgin' 1 D, Mert Ocak², Burak Bilecenoglu³, Ayşe Işıl Orhan ${ }^{4}$ \\ 'Department of Pediatric Dentistry, Faculty of Dentistry, Ankara University, Ankara, Turkey \\ ${ }^{2}$ Department of Anatomy, Faculty of Dentistry, Ankara University, Ankara, Turkey \\ ${ }^{3}$ Department of Anatomy, Faculty of Medicine, Ankara Medipol University, Ankara, Turkey \\ ${ }^{4}$ Department of Pediatric Dentistry, Faculty of Dentistry, Ankara Yıldırım Beyazıt University, Ankara, Turkey
}

\begin{abstract}
INTRODUCTION: In order to obtain a good prognosis in resin restorations, a strong adhesion not allowing leakage between tooth tissues and restoration should be provided. Effectiveness of universal adhesives on leakage in primary teeth compomer restorations has not been studied.

ОвJеCтIVEs: The objective of this study was to evaluate sealing ability of a universal adhesive used with different etching modes after 1- and 3-year of artificial aging in compomer restorations of primary teeth.

MATERIAL AND METHODS: Sixty-three extracted mandibular primary second molars were used in the study. Class II box cavities $(3 \mathrm{~mm} \times 3 \mathrm{~mm} \times 1.5 \mathrm{~mm})$ were prepared in each tooth. Then, teeth were divided into three groups $(n=21)$, including total-etch, self-etch, and selective-etch modes. All teeth were restored with compomer (Dyract Extra, Dentsply; Konstanz, Germany) after universal adhesive (Prime \& Bond Elect Universal, Denstsply; Milford, USA) application. Teeth were divided into three sub-groups $(n=7)$ with the following three different aging protocols: $24 \mathrm{~h}$ water storage, 1-year aging, and 3-year aging with chewing simulator (Esetron Chewing Simulator; Ankara, Turkey). 50\% silver nitrate solution was applied as a tracer, and its' penetration was analyzed in mm3 using micro-computed tomography system (SkyScan 1275; Kontich, Belgium). Data was analyzed with Kruskal-Wallis $\mathrm{H}$ and Friedman tests.

RESULTS: One-year aging significantly increased the leakage in self-etch group of samples $\left(0.197 \pm 0.49 \mathrm{~mm}^{3}\right)$ compared to the total-etch $\left(0.001 \pm 0.000 \mathrm{~mm}^{3}\right)$ and selective-etch $\left(0.001 \pm 0.000 \mathrm{~mm}^{3}\right)$ groups $(p<0.05)$. There was no difference between the groups at baseline and after the 3 -year artificial aging $(p>0.05)$.

ConcLusions: Self-etch mode of adhesive revealed higher micro-leakage levels at all examination intervals; however, the difference was only significant after the 1-year aging. It can be concluded that universal adhesives can be used with all etching modes in compomer restorations.
\end{abstract}

KEY WORDS: compomer, micro-leakage, universal adhesive.

J Stoma 2021; 74, 4: 236-242

DOI: https://doi.org/10.5114/jos.2021.111657

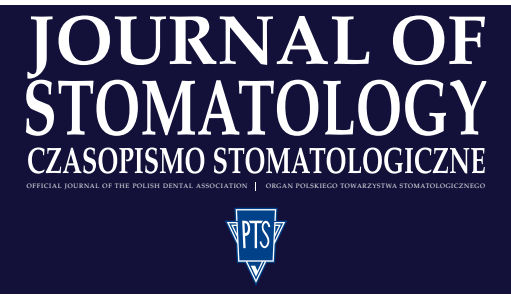

AdDress For Correspondence: Tuğba Bezgin, Ankara Üniversitesi, Diş Hekimliği Fakültesi, Pedodonti Ana Bilim Dalı, Beşevler, Ankara 06500, Turkey, phone: + 9031229656 60, fax: + 9031221239 54, e-mail: cetintugba@yahoo.com

ReCEIVED: 28.10.2021 • ACCEPTED: 15.11.2021 • PUBlished: 30.11.2021 


\section{INTRODUCTION}

A significant progress has been achieved lately in the production of adhesive restorative materials that can bond onto hard tissues of the teeth. Any well-functioning restorative material should provide adhesion to dental hard tissues, support the remaining tooth tissue, provide full sealing, and edge compliance to prevent microleakage $[1,2]$. Pediatric patients and parents increasingly demand restorations to be both esthetically pleasing and functional [3-5]. The use of tooth-colored restorative materials, together with adhesive systems, is often preferred as it allows for minimal cavity preparation in restoration of the primary teeth. However, despite the continuing developments in resin restorative materials, the desired retention times in such restorations have not been achieved [6-8]. Longer lasting restorations, especially in pediatric dentistry, are needed as increasingly younger children develop dental caries [9-11].

Durability of dental restorations is based on a stable adhesion between resin-based materials and dental tissues [12]. The formation of resin tags into micro-porosities created with acid etching, is an important mechanism for micro-mechanical adhesion of resin-based materials to enamel. Owing to this superior bonding, total-etch systems are still considered the gold standard. However, self-etch adhesives are quick and simple to apply, and are less technique-sensitive than total-etch systems. Short chair-time is an important factor while treating pediatric patients. In addition, it is believed that the risk of moisture contamination decreases with shorter treatment time $[13,14]$. However, self-etch systems may prove insufficient adhesion on the enamel surface. Involving the application of acid, total-etch systems work well on the enamel, as it ensures thorough etch patterns resulting in sufficient bonding. Ideally, the acidic resin in self-etch systems should be able to remove the smear layer on the enamel and spread over the tissue. However, high inorganic content of the enamel buffers against acidic resin. Therefore, self-etch adhesives are less successful in enamel than they are in dentin [12].

The relatively new multi-mode universal adhesives are designed to be used via etch-and-rinse technique or self-etch procedure. Manufacturers claim that there is no difference in bonding quality. Selective-etching mode is also possible for this type of adhesive $[12,15]$.

\section{OBJECTIVES}

Although there are studies investigating bonding strength or micro-leakage of universal adhesives with different application techniques [16-19], the effectiveness of this relatively new adhesive on leakage in compomer restorations of primary teeth has not been studied, apart from their common utilization as a direct restorative material in primary teeth $[6,20]$. In addition, structural differences between primary and permanent teeth, such as the thick layer of prismless enamel in primary teeth, is also believed to affect the adhesion efficiency in primary teeth [21-23]. Therefore, the objective of this study was to evaluate the sealing ability of a universal adhesive used with different etching modes after 1- and 3-year artificial aging in class II compomer restorations of primary molar teeth. The null hypothesis tested in the study, included 1) no differences in micro-leakage values exist between different application modes; and 2) no differences in micro-leakage values exist between different aging times.

\section{MATERIAL AND METHODS}

Caries-free extracted primary second molar teeth were used in the study. Ethical approval was received from the Institutional Review Board of Ankara University, Faculty of Dentistry (No. 36290600/18), and an informed consents were obtained from participants and their parents. To determine differences between the study groups, power calculation was applied. The results indicated that a minimum of 63 teeth were required with effect size of $0.5, \alpha$ significance level of $5 \%$ (0.05), and $\beta$ significance level of $20 \%(0.20)$ to achieve an $80 \%$ power. Until the time of the experiment, the extracted teeth were stored in a glass jar with distilled water at $4^{\circ} \mathrm{C}$, for a maximum of 6 months.

\section{PREPARATION OF THE SAMPLES}

Standardized class II box cavities $(3 \mathrm{~mm} \times 3 \mathrm{~mm} \times$ $1.5 \mathrm{~mm}$ ) were prepared in each tooth. Then, teeth were divided into three groups $(n=21)$, each assigned to different etching protocols: total-etch, self-etch, and selective-etch.

\section{TOTAL-ETCH GROUP}

Enamel and dentin surfaces of 21 teeth were etched with $37 \%$ phosphoric acid (Pentron Clinical; CA, USA) for 30 seconds and 15 seconds, respectively. They were then rinsed for 15 seconds, and dried by using an air spray for 5 seconds. Prime \& Bond Elect Universal (Dentsply Caulk Milford; DE, USA) was applied as a thin layer as per manufacturer recommendations, using the disposable micro-brush applicator tip. The applied adhesive was agitated for 20 seconds with the micro-brush. The teeth were dried with a light air spray for 5 seconds to remove excess solvent, and polymerized for $10 \mathrm{sec}$ onds with a light source at a power of $1,500 \mathrm{~mW} / \mathrm{cm}^{2}$ LED (light emitting diode, Radii plus, SDI; Australia). Metal matrix bands (Kerr-Hawe; Bioggio, Switzerland) were placed on all teeth to restore the proximal walls. Compomer (Dyract Extra, Dentsply Caulk Milford; DE, 
USA) was placed in homogeneous non-void layers of $1.5 \mathrm{~mm}$ using incremental technique. Each layer was polymerized by light curing unit for 20 seconds.

\section{SELECTIVE-ETCH GROUP}

After the preparation of 21 teeth cavities, enamel surfaces only were etched with $37 \%$ phosphoric acid for 30 seconds. Cavities were rinsed for 15 seconds, and dried by using an air spray for 5 seconds. The samples were then treated with a universal adhesive agent and compomer restorations, as described in the previous group.

\section{SELF-ETCH GROUP}

Following cavity preparation in 21 teeth, Prime \& Bond Elect Universal was applied to the entire cavity in a thin layer. Cavities were dried using light air spray and polymerized by light curing unit for 10 seconds at a power of $1,500 \mathrm{~mW} / \mathrm{cm}^{2}$ LED (light emitting diode, Radii plus, SDI; Australia). Restorations were made as described for other groups.

The teeth were then polished with discs (Sof-Lex, 3M ESPE; St. Paul, MN, USA) and kept in distilled water in an etuve at $37^{\circ} \mathrm{C}$ for 24 hours. The teeth were divided into three sub-groups $(n=7)$ as per aging protocols: baseline (no aging, control group), 1-year aging, and

TABLE 1. Control and study groups

\begin{tabular}{|l|c|c|c|}
\hline & $\begin{array}{c}\text { No aging } \\
\text { (baseline) }\end{array}$ & $\begin{array}{c}\text { 1-year aging } \\
(\mathbf{2 5 0 , 0 0 0} \\
\text { cycles) }\end{array}$ & $\begin{array}{c}\text { 3-year aging } \\
\text { (750,000 } \\
\text { cycles) }\end{array}$ \\
\hline Total-etch $(n=21)$ & 7 & 7 & 7 \\
\hline Selective-etch $(n=21)$ & 7 & 7 & 7 \\
\hline Self-etch $(n=21)$ & 7 & 7 & 7 \\
\hline
\end{tabular}

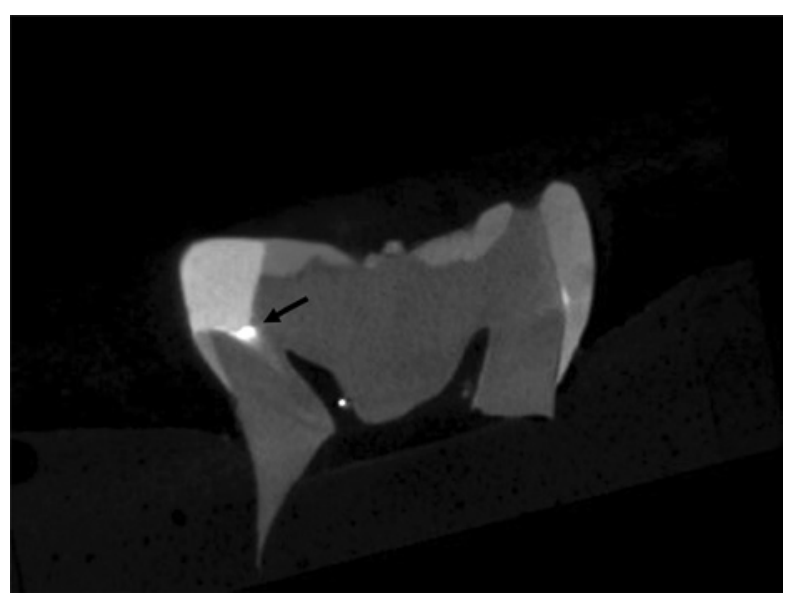

FIGURE 1. Representative image of micro-leakage evaluation obtained from micro-computed tomography. Black arrow indicates the silver nitrate-penetration 3-year aging, with a chewing simulator (Esetron Chewing Simulator, Ankara, Turkey).

\section{AGING PROTOCOLS}

To prevent leaks, the root tips of all samples were sealed with the same adhesive and a flowable composite resin (Filtek Supreme XT Flow, 3M ESPE; St. Paul MN, USA). For the chewing simulation, cylindrical plastic molds (3 cm in length, $2.5 \mathrm{~cm}$ in diameter) were cast to match with the dedicated slot of the chewing simulator to prepare acrylic blocks where the teeth would be embedded in for aging. The teeth were embedded at the center of acrylic blocks, with occlusal surfaces horizontal and cavities above the surface of acrylic blocks, using auto-polymerizing acrylic.

Twenty-one samples from two groups (42 samples in total) were dynamically loaded in a dual-axle chewing simulator (Esetron Chewing Simulator, Ankara, Turkey), and the simulation was controlled by a computer to mimic cycling chewing forces. Chewing forces of the posterior region were simulated applying a force of $50 \mathrm{~N}$ at a frequency of $1.6 \mathrm{~Hz}$. The samples were subjected to 250,000 chewing cycles for each one-year aging period in intra-oral simulation environment, with temperatures ranging between $5^{\circ} \mathrm{C}$ to $55^{\circ} \mathrm{C}[24]$.

Table 1 shows the control and study groups. Seven samples from each group were aged worth of one year (21 samples in total) and three years (21 samples in total). Seven samples from each group were designated as the control group, and no aging simulation was done. Samples in the control group were immersed in a penetrating paint ( $50 \%$ silver nitrate solution) after being kept in etuve for 24 hours.

\section{MICRO-LEAKAGE EVALUATION}

The surface of each sample was painted with two layers of nail polish in different colors for each group, up to $1 \mathrm{~mm}$ away from the restoration edges. All samples were kept in the dark for 12 hours in a $50 \% \mathrm{w} / \mathrm{w}$ silver nitrate solution $\left(\mathrm{AgNO}_{3}\right)$ (Merckb 101510 Silver Nitrate; Darmstadt, Germany). They were then washed under running water for 2 minutes and kept in photo-enhancing solution (Dental X-Ray Developer, Medley, MDC; Turkey) under fluorescent light for 8 hours. The samples were cleaned with a toothbrush and water.

The volume of silver nitrate penetration was determined in $\mathrm{mm}^{3}$ with a micro-computed tomography system (Micro-CT, SkyScan 1275; Kontich, Belgium) to examine micro-leakage (Figure 1) [25]. The samples were scanned at $100 \mathrm{KVP}, 100 \mathrm{~mA}$ power, $0.1 \mathrm{~mm} \mathrm{Cu}$ filtering, and 0.2 step rotation. To reduce ring artifact, the sensor was air-calibrated before each scan. It took about 2 hours to scan each sample. Software packages NRecon (version 1.6.10.4, SkyScan) and CTAn (version 
TABLE 2. Comparative evaluation of micro-leakage values according to aging protocols

\begin{tabular}{|c|c|c|c|c|c|c|c|}
\hline \multirow[t]{2}{*}{ Group } & \multicolumn{7}{|c|}{ Kruskal Wallis H test } \\
\hline & $n$ & Mean & Median & SD & KWH & $p$-value & \\
\hline \multicolumn{8}{|l|}{ Baseline } \\
\hline Self-etch & 7 & 0.159 & 0.001 & 0.409 & \multirow[t]{3}{*}{3.89} & \multirow[t]{3}{*}{0.142} & \multirow[t]{3}{*}{-} \\
\hline Total-etch & 7 & 0.001 & 0.001 & 0.000 & & & \\
\hline Selective-etch & 7 & 0.001 & 0.001 & 0.000 & & & \\
\hline \multicolumn{8}{|l|}{ 1-year aging } \\
\hline Self-etch & 7 & 0.197 & 0.001 & 0.490 & \multirow[t]{3}{*}{6.62} & \multirow[t]{3}{*}{0.037} & \multirow{3}{*}{$\begin{array}{l}1-2 \\
1-3\end{array}$} \\
\hline Total-etch & 7 & 0.047 & 0.001 & 0.122 & & & \\
\hline Selective-etch & 7 & 0.001 & 0.001 & 0.000 & & & \\
\hline \multicolumn{8}{|l|}{ 3-year aging } \\
\hline Self-etch & 7 & 0.314 & 0.060 & 0.438 & \multirow[t]{3}{*}{3.4} & \multirow[t]{3}{*}{0.183} & \multirow[t]{3}{*}{-} \\
\hline Total-etch & 7 & 0.047 & 0.001 & 0.174 & & & \\
\hline Selective-etch & 7 & 0.021 & 0.001 & 0.052 & & & \\
\hline
\end{tabular}

1.16.1.0, SkyScan) were used to image the samples and perform quantitative measurements. Using NRecon software, radiological artifacts were fixed, and the images collected from the scanner was reconstructed to show two-dimensional slices. For three-dimensional volumetric imaging and measuring the volume of microleakage, CTAn software was employed. Two experienced researchers independently assessed each section. When there was a disagreement between the researchers, parts were re-examined until a consensus was reached.

\section{STATISTICAL ANALYSIS}

Data analysis was performed using SPSS 21 program. Kruskal-Wallis $H$ test was used for comparisons between the groups, and Friedman test was used to calculate group-time interaction differences. The study adopted a significance level of 0.05 .

\section{RESULTS}

Table 2 shows leakage values derived from penetration volumes of $\mathrm{AgNO}_{3}$ in the 63 samples investigated in the study. There was no statistically significant difference between the groups at baseline $(p>0.05)$. One-year aging caused significant increase in leakage in the self-etch group $\left(0.197 \pm 0.49 \mathrm{~mm}^{3}\right)$ compared to the total-etch $\left(0.001 \pm 0.000 \mathrm{~mm}^{3}\right)$ and the selective-etch $(0.001 \pm 0.000$ $\left.\mathrm{mm}^{3}\right)$ groups $(p<0.05)$. There was no difference between the groups at baseline and after 3-year artificial aging $(p>0.05)$ (Table 2).

For each group, leakage values were higher after oneyear and three-year aging compared to baseline. However, the increase was not statistically significant $(p>0.05)$ (Tables 3-5).

\section{DISCUSSION}

The first null hypothesis that anticipated no significant difference in micro-leakage values between different etching modes was rejected, as the self-etch mode of the universal adhesive revealed statistically higher micro-leakage values after 1-year aging. However, in the 3 -year aging group, there was no statistically significant difference between various etching modes. The second null hypothesis that anticipated no significant difference in micro-leakage values among aging times was accepted, because aging did not affect micro-leakage values statistically when groups were evaluated separately.

Due to a lack of data assessing the degree of microleakage in compomers used in combination with universal adhesives in primary teeth, comparisons may be drawn with previous in vitro and in vivo studies using permanent teeth. In several in vitro studies, etch-andrinse mode was found to be better than self-etch mode in terms of bonding strength, where different universal adhesives were used together with composite resins [16-18, 26]. In addition, less marginal staining findings were obtained with etch-and-rinse mode in in vivo studies, indicating less leakage in long-term follow-up [27,28]. This can be explained by the use of phosphoric acid in etch-and-rinse method, which enables better enamel demineralization. This promotes the increase of surface area and wettability, hence increasing micro-mechanical adaptation. However, mild acidity of universal adhesives $(\mathrm{pH} \geq 2.5)$ may reduce enamel bonding when used in self-etch mode [19].

Similar to our findings, Signore et al. [19] found statistically significantly more micro-leakage in self-etch mode in a study, where etch-and-rinse and self-etch modes of a universal adhesive in short-term time were compared. However, our study found no difference be- 
TABLE 3. Micro-leakage values in $\mathrm{mm}^{3}$ according to aging protocols in total-etch group

\begin{tabular}{|c|c|c|c|c|c|c|c|}
\hline \multirow[t]{2}{*}{ Group } & \multicolumn{6}{|c|}{ Total-etch } & \multirow{2}{*}{$\begin{array}{l}\text { Friedman test } \\
\qquad p \text {-value }\end{array}$} \\
\hline & $n$ & Mean & Median & Minimum & Maximum & SD & \\
\hline Baseline & 7 & 0.001 & 0.001 & 0.001 & 0.001 & 0.000 & \multirow{3}{*}{0.607} \\
\hline 1-year aging & 7 & 0.047 & 0.001 & 0.001 & 0.325 & 0.122 & \\
\hline 3-year aging & 7 & 0.067 & 0.001 & 0.001 & 0.462 & 0.174 & \\
\hline
\end{tabular}

TABLE 4. Micro-leakage values in $\mathrm{mm}^{3}$ according to aging protocols in selective-etch group

\begin{tabular}{|c|c|c|c|c|c|c|c|}
\hline \multirow[t]{2}{*}{ Group } & \multicolumn{6}{|c|}{ Selective-etch } & \multirow{2}{*}{$\begin{array}{l}\text { Friedman test } \\
\qquad p \text {-value }\end{array}$} \\
\hline & $n$ & Mean & Median & Minimum & Maximum & SD & \\
\hline Baseline & 7 & 0.001 & 0.001 & 0.001 & 0.001 & 0.000 & \multirow{3}{*}{0.135} \\
\hline 1-year aging & 7 & 0.001 & 0.001 & 0.001 & 0.001 & 0.000 & \\
\hline 3-year aging & 7 & 0.021 & 0.001 & 0.001 & 0.139 & 0.052 & \\
\hline
\end{tabular}

TABLE 5. Micro-leakage values in $\mathrm{mm}^{3}$ according to aging protocols in self-etch group

\begin{tabular}{|c|c|c|c|c|c|c|c|}
\hline \multirow[t]{2}{*}{ Group } & \multicolumn{6}{|c|}{ Self-etch } & \multirow{2}{*}{$\begin{array}{c}\text { Friedman test } \\
\qquad p \text {-value }\end{array}$} \\
\hline & $n$ & Mean & Median & Minimum & Maximum & SD & \\
\hline Baseline & 7 & 0.159 & 0.001 & 0.001 & 1.085 & 0.409 & \multirow{3}{*}{0.623} \\
\hline 1-year aging & 7 & 0.197 & 0.001 & 0.001 & 1.308 & 0.490 & \\
\hline 3-year aging & 7 & 0.314 & 0.060 & 0.001 & 1.089 & 0.438 & \\
\hline
\end{tabular}

tween etching mode groups in long-term aging. This may be due to the fact that aging initiates leakage in etch-and-rinse and selective-etch groups as well. In line with the results of the present study, Marchesi et al. [29] reported that etch-and-rinse mode of a universal adhesive demonstrated better results in short-term evaluation compared to self-etch mode; however, long-term aging resulted in increased leakage expression. The authors explained these results with the fact that universal adhesives contain functional monomers, which help establish a long-term successful chemical bond with dentine collagen scaffold. However, when phosphoric acid is applied to the dentin as in total-etch mode, partially infiltrated collagens would be susceptible to degradation by matrix metalloproteinases in long-term [30, 31]. In this study, although not statistically significant, the selective-etch mode showed less micro-leakage rates than the total-etch group. Better results obtained in this group may be explained by the fact that only the enamel, not the dentin, was etched. Similarly, Antoniazzi et al. [17] recommended the selective etching mode in primary teeth in testing micro-shear bond strength of a universal adhesive.

To the best of our knowledge, the only study examining leakage in primary teeth using universal adhesives is the study by Lenzi et al. [16]. Even though the researchers used composite resin for restoration, the study presented a comparative evaluation of the bonding per- formance and nano-leakage values of a universal adhesive used with different etching modes. The authors did not adopt an aging protocol in this in vitro study. The amount of nano-leakage after 24-hour water storage for a universal adhesive in self-etch mode was higher than in etch-and-rinse and selective-etch groups, which also showed the lowest bond strength values. Whereas in our study, although the self-etch group demonstrated more micro-leakage after 24 hours in the control group (baseline), there was no statistically significant difference between the groups. This can be explained by the use of different methodology, adhesive agents, and restorative materials.

Clinically, micro-leakage occurs with fatigue. Fatigue is a form of failure in structures subjected to dynamic loads, and is affected by stress, restoration design, condition and configuration of the restoration surface, and environmental factors. Fatigue that occurs as a result of repeated forces causes micro-cracks and adhesive failure on the surface between the tooth and the restoration [32]. At the same time, restorations in the mouth are constantly exposed to changes in temperature and $\mathrm{pH}$. For this reason, in vitro studies should include aging protocols that would best simulate the oral cavity. For this purpose, a proper simulation that imitates chewing system should be able to apply predetermined forces to the material, with a certain number of repetitions while moving in a single- 
or multiple-axis. The present study utilized a dual-axis chewing simulator for aging in order to assume not only cyclic loading and wet conditions of the oral cavity, but also the thermal changes that these restorations are subjected during daily function [33].

In this study, micro-leakage was evaluated with a micro-CT scan. Micro-CT is preferred because of its' ability to measure the sealing capabilities of dental restorative materials three-dimensionally. Silver nitrate salts, which are radio-opaque and have small ion size, provide satisfactory results with a good penetration capacity for assessing loss of marginal seal $[25,34]$. Micro-CT scan has been reported to have a good sensitivity to evaluate pattern of $\mathrm{AgNO}_{3}$ infiltration at the resin-tooth interface [35].

This study presents a variety of limitations. Our results were obtained under in vitro conditions, which enable direct access to the prepared tooth samples. Moreover, a greater sample size would result in more differentiation in leakage analysis. As aging protocol and micro-CT analysis are expensive and time-consuming, the sample size was relatively small in this study. In addition, the longest aging period in this study was 3 years. Higher aging durations would have resulted in more statistically significant differences. There is a need for other in vitro studies comparatively evaluating bond strength and micro-leakage total-etch, self-etch, and selective-etch modes of universal adhesives in compomer restorations, and also long-term in vivo studies for clinical results.

\section{CONCLUSIONS}

The self-etch mode of the universal adhesive showed higher micro-leakage levels at all examination intervals. The addition of an etching step (total-etch or selectiveetch) resulted in a significantly less short-term microleakage. However, the difference was only significant after 1-year aging. After the long-term aging protocol, with the increase of leakage in etched groups, no statistically significant difference was found between the etching protocols. It can be concluded that universal adhesives are reliable for working under different etching modes in compomer restorations in pediatric dental patients.

\section{ETHICAL APPROVAL}

The study has obtained an approval of bioethics committee, with approval number of 36290600/18.

\section{CONFLICT OF INTEREST}

The authors report no conflict of interest.

\section{References}

1. Puckett AD, Fitchie JG, Kirk PC, Gamblin J. Direct composite restorative materials. Dent Clin North Am 2007; 51: 659-675.
2. Yengopal V, Harneker SY, Patel N, Siegfried N. Dental fillings for the treatment of caries in the primary dentition. Cochrane Database Syst Rev 2009; 2: CD004483.

3. Zimmerman JA, Feigal RJ, Till MJ, Hodges JS. Parental attitudes on restorative materials as factors influencing current use in pediatric dentistry. Pediatr Dent 2009; 31: 63-70.

4. Holsinger DM, Wells MH, Scarbecz M, Donaldson M. Clinical evaluation and parental satisfaction with pediatric zirconia anterior crowns. Pediatr Dent 2016; 38: 192-197.

5. Pani SC, Saffan AA, AlHobail S, Bin Salem F, AlFuraih A, AlTamimi M. Esthetic concerns and acceptability of treatment modalities in primary teeth: a comparison between children and their parents. Int J Dent 2016; 2016: 3163904.

6. Buerkle V, Kuehnisch J, Guelmann M, Hickel R. Restoration materials for primary molars-results from a European survey. J Dent 2005; 33: 275-281.

7. Hickel R, Kaaden C, Paschos E, Buerkle V, García-Godoy F, Manhart J. Longevity of occlusally-stressed restorations in posterior primary teeth. Am J Dent 2005; 18: 198-211.

8. Zhou W, Liu S, Zhou X, et al. Modifying adhesive materials to improve the longevity of resinous restorations. Int J Mol Sci 2019; 20: 723 .

9. Dye BA, Hsu KL, Afful J. Prevalence and measurement of dental caries in young children. Pediatr Dent 2015; 37: 200-216.

10. Kale S, Kakodkar P, Shetiya S, Abdulkader R. Prevalence of dental caries among children aged 5-15 years from 9 countries in the Eastern Mediterranean Region: a meta-analysis. East Mediterr Health J 2020; 26: 726-735.

11. Kazeminia M, Abdi A, Shohaimi S, et al. Dental caries in primary and permanent teeth in children's worldwide, 1995 to 2019: a systematic review and meta-analysis. Head Face Med 2020; 16: 22.

12. Perdigão J, Araujo E, Ramos RQ, Gomes G, Pizzolotto L. Adhesive dentistry: current concepts and clinical considerations. J Esthet Restor Dent 2021; 33: 51-68.

13. Cho BH, Dickens SH. Effects of the acetone content of single solution dentin bonding agents on the adhesive layer thickness and the microtensile bond strength. Dent Mater 2004; 20: 107-115.

14. Tay FR, Kwong SM, Itthagarun A, et al. Bonding of a self-etching primer to non-carious cervical sclerotic dentin: interfacial ultrastructure and microtensile bond strength evaluation. J Adhes Dent 2000; 2: 9-28.

15. Chen C, Niu LN, Xie H, et al. Bonding of universal adhesives to dentine - old wine in new bottles? J Dent 2015; 43: 525-536.

16. Lenzi TL, Raggio DP, Soares FZ, Rocha Rde O. Bonding performance of a multimode adhesive to artificially-induced caries-affected primary dentin. J Adhes Dent 2015; 17: 125-131.

17. Antoniazzi BF, Nicoloso GF, Lenzi TL, Soares FZ, Rocha Rde O. Selective acid etching improves the bond strength of universal adhesive to sound and demineralized enamel of primary teeth. J Adhes Dent 2016; 18: 311-316.

18. Atalay C, Uslu A, Yazici AR. Does laser etching have an effect on application mode of a universal adhesive? - A microleakage and scanning electron microscopy evaluation. Microsc Res Tech 2021; 84: 125-132.

19. Signore A, Solimei L, Arakelyan MG, Arzukanyan AV, De Angelis N, Amaroli A. Marginal quality of a full-body bulk-fill composite placed with a universal adhesive system in etch-and-rinse and selfetch mode: an in vitro study. J Clin Exp Dent 2021; 13: e835-844.

20. Farozi AM, Lupi-Pegurier L, Muller M, Weerheijm KL. Restorative materials used on primary teeth: a comparative study between two European universities: Nice and Amsterdam. ASDC J Dent Child 2001; 68: 339-343.

21. Hinding JH, Sveen OB. A scanning electron microscope study of the effects of acid conditioning on occlusal enamel of human permanent and deciduous teeth. Arch Oral Biol 1974; 19: 573-576.

22. Nordenvall KJ, Brännström M, Malmgren O. Etching of deciduous teeth and young and old permanent teeth. A comparison between 15 and 60 seconds of etching. Am J Orthod 1980; 78: 99-108. 
23. Christopher A, Krishnakumar R, Reddy NV, Rohini G. Effect of enamel deproteinization in primary teeth. J Clin Pediatr Dent 2018; 42: 45-49.

24. Kern M, Strub JR, Lü XY. Wear of composite resin veneering materials in a dual-axis chewing simulator. J Oral Rehabil 1999; 26: 372-378.

25. Aydın F, Demirel G, Bilecenoğlu B, Ocak M, Gür G. Effect of different artificial aging protocols on marginal sealing ability of selfetch dental adhesives: micro-computed tomography evaluation. J Adhes Sci and Tech 2020; 34: 388-399.

26. Rosa WL, Piva E, Silva AF. Bond strength of universal adhesives: a systematic review and meta-analysis. J Dent 2015; 43: 765-776.

27. Ruschel VC, Shibata S, Stolf SC, et al. Eighteen-month clinica study of universal adhesives in noncarious cervical lesions. Oper Dent 2018; 43: 241-249.

28. Atalay C, Ozgunaltay G, Yazici AR. Thirty-six-month clinical evaluation of different adhesive strategies of a universal adhesive. Clin Oral Investig 2020; 24: 1569-1578.

29. Marchesi G, Frassetto A, Mazzoni A, et al. Adhesive performance of a multi-mode adhesive system: 1-year in vitro study. J Dent 2014; 42: 603-612.

30. De Munck J, Van den Steen PE, Mine A, et al. Inhibition of enzymatic degradation of adhesive-dentin interfaces. J Dent Res 2009; 88: 1101-1106.

31. Mazzoni A, Scaffa P, Carrilho M, et al. Effects of etch-and-rinse and self-etch adhesives on dentin MMP-2 and MMP-9. J Dent Res 2013; 92: 82-86.

32. Drummond JL, Lin L, Al-Turki LA, Hurley RK. Fatigue behaviour of dental composite materials. J Dent 2009; 37: 321-330.

33. Kohyama K, Hatakeyama E, Sasaki T, Dan H, Azuma T, Karita K. Effects of sample hardness on human chewing force: a model study using silicone rubber. Arch Oral Biol 2004; 49: 805-816.

34. Rizzante FAP, Sedky RAF, Furuse AY, Teich S, Ishikiriama SK Mendonça G. Validation of a method of quantifying 3D leakage in dental restorations. J Prosthet Dent 2020; 123: 839-844.

35. Carrera CA, Lan C, Escobar-Sanabria D, et al. The use of microCT with image segmentation to quantify leakage in dental restorations. Dent Mater 2015; 31: 382-390. 